\title{
Surgical resection and outcome of pancreatic cystic neoplasms in China: analysis of a 16-year experience from a single high-volume academic institution
}

\author{
Xueli Bai, Longyun Ye, Qi Zhang, Pankaj Prasoon, Ji Wang and Tingbo Liang*
}

\begin{abstract}
Background: To investigate the clinicopathological features of surgically resected pancreatic cystic neoplasms (PCNs) at a single institution in China.

Methods: The medical charts of patients who operated in the Second Affiliated Hospital, Zhejiang University School of Medicine between 1 January 1997 and 30 June 2013, were pathologically shown to have PCNs.

Results: There was a reliable increase trend not just in the overall number of patients ( 3 to 75 ) but additionally in the number of incidentally diagnosed patients across the periods (33.3\% to 48.0\%). In 83 of 111 cases, preoperative diagnoses matched with pathology, whereas the remaining cases (16/28) were misdiagnosed as pancreatic cancer. The proportion of malignancy in mucin producing neoplasms was $24.3 \%$ ( 9 out of 37). Elevated serum carbohydrate antigen (CA19-9) or carcinoembryonic antigen (CEA) was independently associated with malignancy. The overall survival rate was $96.4 \%$.

Conclusions: The proportion of PCNs within this series differs with that revealed in Western countries. Appropriate preoperative differential diagnosing of PCNs remains challenging. It is strongly recommended that patients with elevated CA19-9 or CEA levels undergo surgical resection.
\end{abstract}

Keywords: Pancreatic cystic neoplasms, Surgical resection, Malignancy, Preoperative diagnosis, Postoperative complication

\section{Background}

The widespread use of abdominal imaging in China in the past decade has resulted in a dramatic increase in the identification of pancreatic cystic neoplasms (PCNs). This is similar to Western series such as the United States, in which cross sectional imaging has been used extensively for a longer period of time. In the Western series it has been reported that $2.6 \%$ of patients undergoing an abdominal CT scan are found to have a cystic neoplasm and another study reports $13 \%$ of patients undergoing abdominal MRI scans have cystic neoplasms

\footnotetext{
* Correspondence: liangtingbo@zju.edu.cn

Department of Hepatobiliary-Pancreatic Surgery, Second Affiliated Hospital, School of Medicine, Zhejiang University, 88 Jiefang St, Hangzhou 310009, Zhejiang, China
}

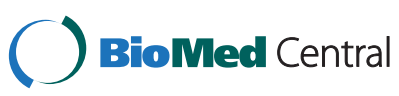

(C) 2014 Bai et al.; licensee BioMed Central Ltd. This is an Open Access article distributed under the terms of the Creative Commons Attribution License (http://creativecommons.org/licenses/by/2.0), which permits unrestricted use, distribution, and reproduction in any medium, provided the original work is properly credited. The Creative Commons Public Domain Dedication waiver (http://creativecommons.org/publicdomain/zero/1.0/) applies to the data made available in this article unless otherwise stated.
[1-4]. The incidence of pancreatic cystic lesions is about 1 in 100 hospitalized patients in the United States [5].

$\mathrm{PCN}$ exists as a spectrum of diseases that range from completely benign to frankly malignant. Thus, careful selection for operative intervention is necessary for optimal outcomes in the management of patients with PCN. Currently, guidelines exist that guide selection for resection and are followed by most experienced centers [6]. These criteria are based on clinical features, imaging characteristics, and findings on endoscopic ultrasound/ fine needle aspiration (EUS/FNA).

To date very few Chinese studies concerning surgical treatment of PCNs have been reported. It is likely that based on differences in genetic backgrounds, risk factors, and use of cross sectional imaging, significant difference exists in the incidence and indications for resection of 
PCN between Chinese and Western patients. Therefore the goal of this study is to report the experience of patients undergoing resection of a $\mathrm{PCN}$ at a single university-based high-volume pancreatic surgery center in China. In this study, we retrospectively reviewed and analyzed the data for 111 patients who underwent operations and were pathologically confirmed to have four major types of PCNs: intraductal papillary mucinous neoplasm (IPMN), mucinous cystic neoplasm (MCN), serous cystic neoplasm (SCN), and solid pseudopapillary neoplasm (SPN). To our knowledge, this is the largest series of surgically resected PCNs reported in English from China to date.

\section{Methods}

This study was approved by the Ethics Committee of the Second Affiliated Hospital, School of Medicine, Zhejiang University and was performed according to the Declaration of Helsinki [7]. Records of patients who underwent surgical resection and were pathologically proven to have IPMN, MSC, SCN, or SPN between 1 January 1997, and 30 June 2013 at the Second Affiliated Hospital of Zhejiang University School of Medicine (China) were retrospectively reviewed and analyzed. The preoperative diagnosis, which was based on clinical manifestations, serum tumor markers, and the results of imaging including computed tomography (CT), magnetic resonance imaging (MRI) or magnetic resonance cholangiopancreatography (MRCP), were compared with the postoperative pathological diagnosis.

A serum carbohydrate antigen 199 (CA19-9) level of more than $37 \mathrm{U} / \mathrm{L}$ and a carcinoembryonic antigen (CEA) level of more than $5 \mathrm{ng} / \mathrm{mL}$ were considered to be elevated. Pancreatic fistula was diagnosed according to the International Study Group on Pancreatic Fistula criteria [8].

In the final pathologic reports, cystic neoplasms were classified according to the World Health Organization classification of the exocrine and endocrine neoplasms of the pancreas [9]. IPMN and MCN were graded based on degree of dysplasia: low-grade, intermediate grade, high-grade (carcinoma in situ (CIS)), and invasive. Serous cystadenocarcinoma was defined by the presence of metastases [10].

Information about recurrence and survival time was obtained via follow-up phone calls and clinical interviews. Statistical analysis was carried out using SPSS version 19.0 (SPSS, Chicago, Illinois, United States). Continuous variables were expressed as medians and ranges and compared using the Mann-Whitney test. Categorical variables were compared using a chi-squared test (or Fisher's exact test). Univariate analyses were conducted using chi-square or Mann-Whitney $U$ tests, as appropriate, and multivariate analysis was performed using forward step-wise logistic regression analysis. Survival analysis was performed using the Kaplan-Meier method, with differences determined by the log-rank test. All tests were two-sided and $P<0.05$ was considered to indicate statistical significance.

\section{Results}

\section{Demographic data and clinical features}

A total of 111 patients were enrolled in this study, including 17 (15.3\%) with IPMNs, 20 (18.0\%) with MCNs, 39 (35.1\%) with SCNs, and 35 (31.5\%) with SPNs (Figure 1). All patients were of Chinese ethnicity. The age of the patients varied from 13 to 81 years, with the median age of 46 years, and $75.7 \%$ were female (Table 1 ). Patients undergoing resection of SPN (median age: 30 years; range: 13 to 59 years) were significantly younger than those in the IPMN group (median age: 71 years; range: 44 to 81 years; $P<0.001$ ), $\mathrm{MCN}$ group (median age: 48 years; range: 24 to 75 years; $P<0.001$ ) and SCN group (median age: 53 years; range: 24 to 78 years; $P<0.001$ ). Meanwhile, the patients with IPMN (median age: 71 years; range: 44 to 81 years) were older than the other patients $(P<0.001)$. Females were more common among SPN (91.4\%, 32 out of 35), MCN (100\%, 20 out of 20 ) and $\operatorname{SCN}(71.8 \%, 28$ out of 39$)$, while IPMN noted a slight male dominance $(76.5 \%, 13$ out of $17 ; P<0.05)$. Sixty-two (55.9\%) patients presented symptoms at admission. Of these, the chief complaint was abdominal pain and distention in 50 patients (45.0\%) and weight loss in 9 (8.1\%) patients; jaundice, nausea, and tumor on palpation were found in 19 cases (17.1\%). There was no significant difference among the various PCNs. Forty-nine patients (44.1\%) were asymptomatic, and their cysts had been

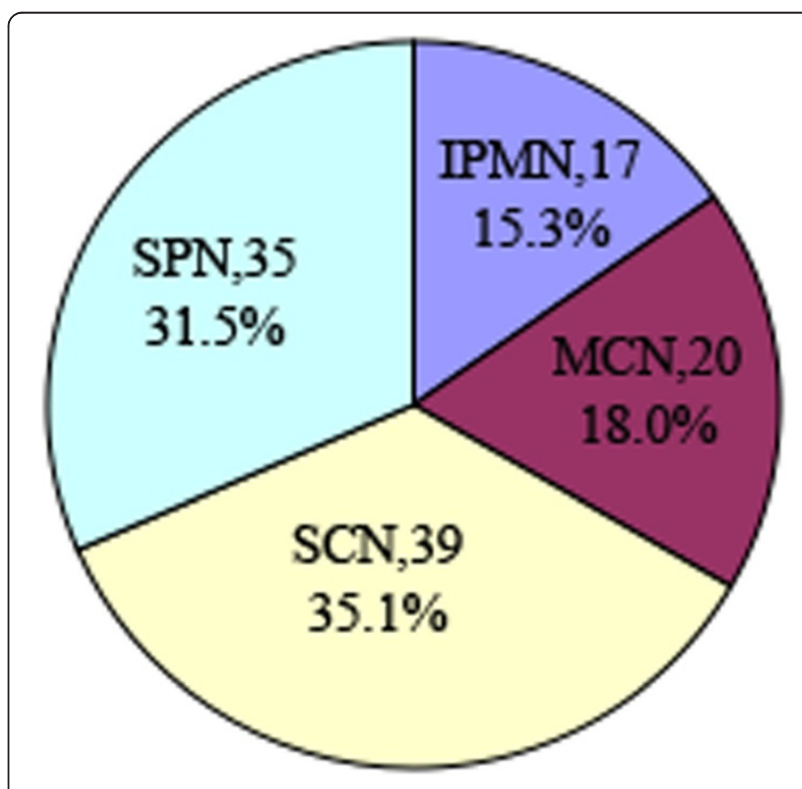

Figure 1 Distribution of PCNs in 111 patients. 
Table 1 Clinical data for the 111 pancreatic cystic neoplasms

\begin{tabular}{|c|c|c|c|c|}
\hline & IPMN $(n=17)$ & $\operatorname{MCN}(n=20)$ & $\operatorname{SCN}(n=39)$ & SPN $(n=35)$ \\
\hline Age, years, median (range) & $71(44-81)$ & $48(24-75)$ & $53(24-78)$ & $30(13-59)$ \\
\hline \multicolumn{5}{|l|}{ Gender, n (\%) } \\
\hline Male & $13(76.5 \%)$ & $0(0 \%)$ & $11(28.2 \%)$ & $3(8.5 \%)$ \\
\hline Female & $4(23.5 \%)$ & $20(100 \%)$ & $28(71.8 \%)$ & $32(91.4 \%)$ \\
\hline Symptoms, n (\%) & $13(76.5 \%)$ & $12(60 \%)$ & $21(53.8 \%)$ & $16(45.7 \%)$ \\
\hline Abdominal pain and distension & 9 & 8 & 18 & 15 \\
\hline Weight loss & 3 & 2 & 3 & 1 \\
\hline Jaundice & 2 & 0 & 1 & 0 \\
\hline Nausea & 1 & 1 & 2 & 5 \\
\hline Tumor palpation & 1 & 4 & 1 & 1 \\
\hline No symptoms, n (\%) & $4(23.5 \%)$ & $8(40 \%)$ & $18(46.2 \%)$ & $19(54.3 \%)$ \\
\hline \multicolumn{5}{|l|}{ Tumor location, n (\%) } \\
\hline Head and/or uncinate process & $12(70.6 \%)$ & $1(5.0 \%)$ & $16(41.0 \%)$ & $14(40.0 \%)$ \\
\hline Neck & $2(11.8 \%)$ & $1(5.0 \%)$ & $6(15.4 \%)$ & $3(8.6 \%)$ \\
\hline Body and/or tail & $3(17.6 \%)$ & $18(90.0 \%)$ & $17(43.6 \%)$ & $18(51.4 \%)$ \\
\hline \multicolumn{5}{|l|}{ Tumor size, cm, median (range) } \\
\hline Length & $3.4(1.8-15.0)$ & $6.0(2.8-18.0)$ & $4.5(1.2-15.0)$ & $4.0(1.2-15.0)$ \\
\hline Width & $2.6(1.0-10.0)$ & $5.0(2.0-10.0)$ & $3.0(1.2-10.0)$ & $3.5(1.2-8.0)$ \\
\hline
\end{tabular}

discovered incidentally either in a routine health examination or on imaging performed for another complaint. The majority of MCNs (90.0\%, 18 out of 20) occurred in the body and tail of the pancreas, whereas SCNs and SPNs tended to be evenly distributed. IPMNs (70.6\%, 12 out of 17) were far more likely to be located in the head. MCNs were significantly larger compared with other cystic neoplasms, with a median length of $6.0 \mathrm{~cm}$ (range: 2.8 to $18.0 \mathrm{~cm} ; P<0.05$ ) and width of $5.0 \mathrm{~cm}$ (range: 2.0 to $10.0 \mathrm{~cm} ; P<0.05)$.

\section{Trends in the incidence and types of PCNs}

In our study, patient characteristics were analyzed and compared among four periods (Table 2) from 1997 to 2013: 1997 to 2000, 2001 to 2004, 2005 to 2008, and 2009 to 2013 . We found a step-wise increase not only in the total number of patients but also in the number of incidentally diagnosed patients. The number of patients who were incidentally diagnosed in the last four years (2009 to 2013) was 36, which is a three-fold increase compared to the 2005 to 2008 period. In the same period (2009 to 2013), almost one-half of the resected PCNs were found incidentally, although it did not reach a significant difference. The median time lapse from the presentation of symptoms and diagnosis of the cystic lesions of the pancreas was one month (range: 0.02 to 144), no significant difference was found between these time periods.

Additionally, the proportion of the pathological types of PCNs varied with time. During 2009 to 2013, SPN and SCN each comprised $36.0 \%$ and $29.3 \%$ of PCNs; however, in 2005 to $2008 \mathrm{SCN}$ was the main pathological type,

Table 2 Trends in surgically resected pancreatic cystic neoplasms

\begin{tabular}{lrrrr}
\hline N & $\mathbf{1 9 9 7 - 2 0 0 0}$ & $\mathbf{2 0 0 1 - 2 0 0 4}$ & $\mathbf{2 0 0 5 - 2 0 0 8}$ & $\mathbf{2 0 0 9 - 2 0 1 3}$ \\
\hline Symptoms, $n(\%)$ & $3(2.7 \%)$ & $6(5.4 \%)$ & $27(24.3 \%)$ & \\
\hline Yes & & & & \\
\hline No & $2(67.6 \%)$ & $4(66.7 \%)$ & $17(63.0 \%)$ & $39(52.0 \%)$ \\
\hline Time interval, months, median (range) & $1(33.3 \%)$ & $2(33.3 \%)$ & $10(37.0 \%)$ & $36(48.0 \%)$ \\
\hline Pancreatic cystic neoplasms, n (\%) & $0.3(0.2-12.0)$ & $1(0.2-48.0)$ & $1(0.1-120.0)$ & $1(0.02-144.0)$ \\
\hline IPMN (intraductal papillary mucinous neoplasm) & & & $5(18.5 \%)$ & $12(16.0 \%)$ \\
\hline MCN (mucinous cystic neoplasm) & $2(66.7 \%)$ & $1(16.7 \%)$ & $3(11.1 \%)$ & $14(18.7 \%)$ \\
\hline SCN (serous cystic neoplasm) & $1(33.3 \%)$ & $1(16.7 \%)$ & $15(55.6 \%)$ & $22(29.3 \%)$ \\
\hline SPN (solid pseudopapillary neoplasm) & 0 & $4(66.7 \%)$ & $4(14.8 \%)$ & $27(36.0 \%)$ \\
\hline
\end{tabular}

*The time lapse from the presentation of symptoms and diagnosis of the cystic lesions of the pancreas. 
accounting for $55.6 \%$ of PCNs $(P<0.05)$, and SPNs only accounted for $14.8 \%$ of PCNs $(P<0.05)$. IPMNs also showed an increasing trend over time: only 5 patients were diagnosed before 2008, while it was confirmed in 12 patients in 2009 to 2013, although it did not reach a statistically significant difference.

\section{Preoperative diagnostic accuracy}

In the preoperative work-up, an abdominal CT scan was performed in 104 of 111 patients (93.7\%), and an MRI or MRCP was used in $27(24.3 \%)$ patients. In addition, EUS/FNA and endoscopic retrograde cholangiopancreatography (ERCP) were performed in $2(1.8 \%)$ and 1 (0.9\%) patients, respectively.

Preoperative diagnoses of 83 patients were approved by pathology, while the remaining 21 (18.9\%, 21/111) were misdiagnosed as pancreatic cancer (in 16 patients), pseudocyst (in 4 patients) and neuroendocrine tumor (in 1 patient). Seven $(6.3 \%, 7 / 111)$ patients were indistinguishable from other PCNs (Table 3).

\section{Surgical intervention and operative complications}

A surgical intervention was performed because of the presence of symptoms in 62 patients. In the other 49 (44.1\%) asymptomatic patients, resection was driven by the suspected malignancy or uncertain diagnosis with tumor size of larger than $3 \mathrm{~cm}$.

In $39 \mathrm{SCNs}, 21$ patents $(53.8 \%)$ were operated on because of clinical symptoms and 11 were operated on because of large tumors (more than $4 \mathrm{~cm}$ ) [11]. Four patients were misdiagnosed as pancreatic cancer, and 3 patients' tumors were indistinguishable from MCNs before the operation.

In total, 50 (45.0\%) distal pancreatectomies (of which 14 procedures were done with preservation of the spleen and 4 were performed laparoscopically), 26 (23.4\%) pancreaticoduodenectomies, 17 (15.3\%) middle pancreatectomies, 15 (13.5\%) enucleations, 1 (0.9\%) pylorus-preserving pancreaticoduodenectomy, 1 (0.9\%) total pancreatectomy, and $1(0.9 \%)$ laparotomy with a diagnostic biopsy were performed (Table 4).

Postsurgical complications occurred in 50 patients (45.0\%), among whom the most common complication was pancreatic fistula (29.7\%, 33 out of 111$)$. The incidence of pancreatic fistula was higher in the SPN group (42.9\%, 15 out of 35), but was not significantly different between the other groups $(P>0.05)$. Other complications included intra-abdominal infection $(14.4 \%, 16$ out of 111$)$, pleural effusion $(11.7 \%$, 13 out of 111$)$, delayed gastric emptying (8.1\%, 9 out of 111$)$, pulmonary infection $(6.3 \%, 7$ out of $111)$, bile leakage (3.6\%, 4 out of 111 ) and wound infection $(2.7 \%, 3$ out of 111$)$. Furthermore, reoperation was necessary in 4 patients $(3.6 \%, 4$ out of 111$) ; 2$ due to hemorrhages, 1 due to bile leakage, and 1 due to pancreatic fistula. The mortality rate in this series was $0.9 \%$ ( 1 out of 111): one patient in the IPMN group who underwent distal pancreatectomy died on the 22nd postoperative day because of pneumonia and septic shock. The median hospital stay after surgery was 17.0 days (range: 7 to 123 days) in 110 patients. In the MCN group, this was 13.0 days (range: 8.0 to 26.0 days), which was significantly shorter than that in the IPMN group (median: 19.0 days; range: 12.0 to 74.0 days; $P<0.05$ ), SCN group (median: 20.0 days; range: 7.0 to 123.0 days; $P<0.05$ ) and SPN group (median: 16.0 days; range: 7.0 to 99.0 days; $P<0.05$ ).

\section{Predictive factors of malignancy in mucin-producing neoplasms}

In mucin-producing neoplasms (IPMNs and MCNs), malignancy was found 9 patients, 6 in IPMNs, and 3 in MCNs. Univariate analysis revealed gender and elevated CA19-9 or CEA level to be significant predictive factors of malignance (Table 5). Multivariate analysis revealed that elevated CA19-9 or CEA levels were independent predictive factors of malignancy $(P<0.05)$ (Table 6).

\section{Follow-up data}

Survival data were collected from all 110 patients, who were followed-up for a median time of 35.67 months (0.9 to 188.23 months). The overall survival rate was $96.4 \%$. Survival analysis showed that the survival rate of SPNs (100\%) and SCNs (100\%) was significantly better than that of IPMNs (87.5\%) and MCNs (90.0\%) (Figure 2).

\section{Discussion}

In this study we have obtained comprehensive data on the trends in PCNs in one single institution in China over the last 16 years. We found an increase in the number of

Table 3 Preoperative diagnosis of pancreatic cystic neoplasms

\begin{tabular}{lllll}
\hline & IPMN $(\mathbf{n}=\mathbf{1 7 )}$ & MCN $(\mathbf{n}=\mathbf{2 0})$ & SCN $(\mathbf{n}=\mathbf{3 9 )}$ & SPN (n= 35) \\
\hline Preoperative diagnosis, n, (\%) & $11(64.7 \%)$ & $17(85 \%)$ & $28(71.8 \%)$ & $27(77.1 \%)$ \\
\hline Misdiagnosis, n, (\%) & $6(35.3 \%)$ & $3(15 \%)$ & $11(28.2 \%)$ & $7(22.9 \%)$ \\
\hline Carcinoma & $5(83.3 \%)$ & & $4(36.5 \%)$ & $7(87.5 \%)$ \\
\hline Neuroendocrine tumor & & & $1(9 \%)$ & \\
\hline Pseudocyst & $1(16.7 \%)$ & $3(100 \%)$ & $6(54.5 \%)$ & $1(12.5 \%)$ \\
\hline Others PCNs & & & & \\
\hline
\end{tabular}


Table 4 Surgical interventions and morbidity

\begin{tabular}{|c|c|c|c|c|}
\hline & IPMN $(n=17)$ & $\operatorname{MCN}(n=20)$ & SCN (n = 39) & SPN $(n=35)$ \\
\hline \multicolumn{5}{|l|}{ Types of resection, $\mathrm{n}(\%)$} \\
\hline Distal pancreatectomy, splenectomy & $2(11.8 \%)$ & $11(55 \%)$ & $11(28.2 \%)$ & $12(34.3 \%)$ \\
\hline Spleen-preserving distal pancreatectomy & $2(11.8 \%)$ & $6(30 \%)$ & $3(7.7 \%)$ & $3(8.6 \%)$ \\
\hline Pancreaticoduodenectomy & $11(64.7 \%)$ & & $6(15.4 \%)$ & $9(25.7 \%)$ \\
\hline Pylorus-preserving pancreaticoduodenectomy & & & $1(2.6 \%)$ & \\
\hline Middle pancreatectomy & & & $12(30.8 \%)$ & $5(14.3 \%)$ \\
\hline Tumor enucleation & $1(5.9 \%)$ & $2(10 \%)$ & $6(15.4 \%)$ & $6(17.1 \%)$ \\
\hline Laparotomy with biopsy & & $1(5 \%)$ & & \\
\hline Total pancreatectomy & $1(5.9 \%)$ & & & \\
\hline Postoperative complications, n (\%) & $8(47.1 \%)$ & $6(30 \%)$ & $15(38.5 \%)$ & $21(60 \%)$ \\
\hline No complications, n (\%) & $9(52.9 \%)$ & $14(70 \%)$ & $24(61.5 \%)$ & $14(40 \%)$ \\
\hline Re-operation (n) & 0 & 0 & $2(5.1 \%)$ & $2(5.7 \%)$ \\
\hline Hospital stay after surgery, days, median (range) & $19.0(12.0-74.0)$ & $13.0(8.0-26.0)$ & $20.0(7.0-123.0)$ & $16.0(7.0-99.0)$ \\
\hline
\end{tabular}

surgically managed PCN cases in the last four years. This is similar to the data for other countries. For example, PCNs were found to represent at least $25 \%$ of resections at the major pancreatic referral centers in the United States in 2003 [12].

A detailed review of previous studies has shown that there is a difference in the relative proportions of

Table 5 Univariate analysis of predictive factors of malignant pancreatic cystic neoplasms

\begin{tabular}{|c|c|c|c|}
\hline & $\begin{array}{r}\text { Malignant } \\
(\mathrm{n}=9)\end{array}$ & $\begin{array}{r}\text { Benign } \\
(\mathrm{n}=28)\end{array}$ & $P$ value \\
\hline Age, years, median (range) & $64(50-77)$ & $49(24-81)$ & 0.051 \\
\hline Gender (n) & & & 0.036 \\
\hline Male & 6 & 6 & \\
\hline Female & 3 & 22 & \\
\hline Symptoms & & & 0.446 \\
\hline Yes & 7 & 17 & \\
\hline No & 2 & 11 & \\
\hline Tumor location (n) & & & 0.573 \\
\hline Head and/or uncinate process & 4 & 8 & \\
\hline Neck & 1 & 2 & \\
\hline Body and/or tail & 4 & 18 & \\
\hline PCN classification & & & 0.251 \\
\hline $\begin{array}{l}\text { IPMN (intraductal papillary } \\
\text { mucinous neoplasm) }\end{array}$ & 6 & 11 & \\
\hline MCN (mucinous cystic neoplasm) & 3 & 17 & \\
\hline $\begin{array}{l}\text { Elevated serum carbohydrate } \\
\text { antigen (CA19-9) or carcinoembryonic } \\
\text { antigen (CEA) }\end{array}$ & & & 0.014 \\
\hline Yes & 7 & 5 & \\
\hline No & 2 & 15 & \\
\hline Tumor size $(\mathrm{cm})$ & & & 0.403 \\
\hline$>3 \mathrm{~cm}$ & 8 & 20 & \\
\hline$\leq 3 \mathrm{~cm}$ & 1 & 8 & \\
\hline
\end{tabular}

different pathologic diagnoses. Coelho et al. [13] reported in 2010 that only 4 (15\%) patients were diagnosed IPMN, and in a series of 599 consecutive patients, Bassi et al. [14] found an IPMN rate of $17 \%$. In our study, IPMN was only diagnosed in $15.3 \%$ of the patients. In contrast to this, a recent study at Massachusetts General Hospital demonstrated that IPMN was the most common type of PCN resected and accounted for nearly one-half of the resected cystic neoplasms in the last five years [15]. Main duct and/or mixed-duct and branchduct IPMN were also reported to comprise $48.6 \%$ of PCNs in the Department of Surgery, University of Verona, Italy, in 2012 [16]. This disagreement between the results may be explained by the following: (1) Due to economic issues, abdominal cross-sectional imaging examination with CT or MRI is not routinely performed in China so far. While most IPMNs are asymptomatic, this may lead to a low detection rate of IPMN. (2) The recognition of IPMN by a pathologist in China is probably not as good as in Western countries. Under these circumstances, IPMN may be misdiagnosed as MCN or pancreatic adenocarcinoma. According to a recent publication on 2564 resected periampullary adenocarcinomas at Johns Hopkins's hospital, the frequency of pancreatic cancer arising from IPMN was $8 \%$ during the 2000s [17]. We cannot exclude the possibility that pancreatic cancers

Table 6 Multivariate analysis of the predictive factors of malignant pancreatic cystic neoplasms

\begin{tabular}{llll}
\hline Variable & p-value & $\begin{array}{l}\text { Odds } \\
\text { ratio (OR) }\end{array}$ & $\mathbf{9 5 \% ~ C l}$ \\
\hline Gender & 0.998 & N/A & N/A \\
\hline $\begin{array}{l}\text { Elevated serum } \\
\text { carbohydrate antigen } \\
\text { (CA19-9) or carcinoembryonic } \\
\text { antigen (CEA) }\end{array}$ & 0.011 & 0.089 & $0.014-0.576$ \\
\hline
\end{tabular}




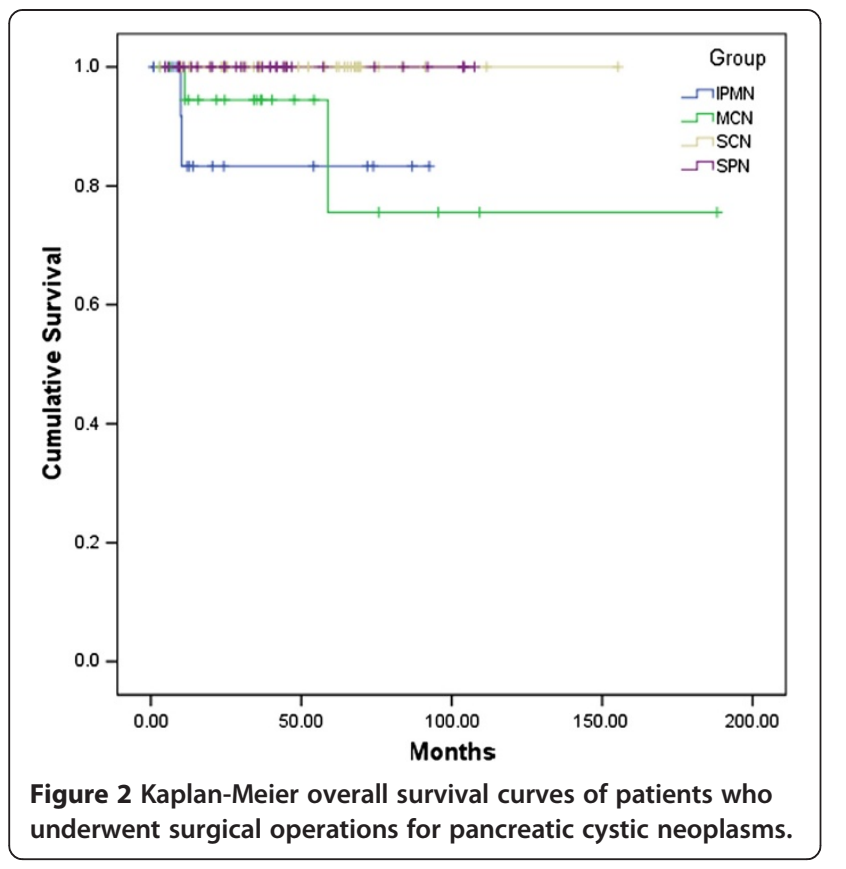

arising from IPMNs have been pathologically diagnosed as cancer while neglecting theirIPMN origin, which may also attribute to the low frequency of IPMN in our series. (3) To date, there are very few publications on PCN from China and the real proportion of each type in China is still unknown. Whether there is a racial difference-related proportion is need to be further investigated. The accuracy of preoperative diagnosis of IPMN was $64.7 \%$ at our hospital during our 16-year experience, whereas the rate of correct diagnosis for IPMN was $80 \%$ in the series in Salvia et al. [16].

IPMN was first differentiated from mucin-producing cystic neoplasms by Ohashi and Murakami in 1990 [18]; before this, the detection rate of IPMNs was only 3\% [19]. It has been established that MCNs do not generally communicate with the pancreatic ducts, a macroscopic feature used in many series as a factor to determine MCN from IPMN [19]. The sole criterion for the diagnosis of MCN is the presence of well-demarcated cysts lined by a mucinproducing columnar epithelium overlying an ovarian-type stroma. Therefore, some authors re-evaluated pathology slides from previous reports. Niedergethmann et al. [20] reported in 2008 that the incidence of incorrect diagnosis was greater in the earlier time period (1996 to 2001) of their study, so they eventually reclassified 54 neoplasms as IPMN among 207 cases, which was $125 \%$ more than the originally diagnosed number. In another study, Tollefson et al. [21] also found that 21 cases of IPMN were misdiagnosed among 84 cases between 1960 and 1980 at the Mayo Clinic (Rochester, Minnesota).

The incidence of SPN reported here is also quite different from that in other reports. SPN is a rare tumor; it forms 1 to $3 \%$ of all pancreatic tumors and 5\% of all cystic tumors of the pancreas according to previous results [22]. This results concur with those of Valsangkar et al's analysis [14] in which only 29 (3.4\%) of the patients were diagnosed with an SPN. The data from another retrospective study of 476 patients who underwent pancreatic resection also documented a lower incidence (8.0\%) in 2012 [16]. Similarly, Bassi et al. [14] reported that the incidence of SPN was $6.5 \%$. On the contrary, a higher prevalence of SPN (31.5\%, 35 out of 111) was found in our series, with $77.1 \%$ of the patients diagnosed in 2009 to 2013. There also has been a higher incidence in the number of SPNs reported in another case series in China (17.3\%) in 2005 [23]. Furthermore, a multi-institutional study in Korea conducted over 13 years that included 1064 cases of pathologically confirmed PCNs, showed that the incidence of SPN was $18.3 \%$ in 2008 [24]. Several large single-institution series on SPN have been reported about in other Asian countries such as Singapore [25], Taiwan [26], India [27], and Japan [28]. This apparent increase in the incidence of SPNs in our study may represent a true increase in incidence resulting from unknown environmental or genetic factors in Asia. On the other hand, there may be possible selection bias; since we included cases of surgically resection only, the increase in the SPN rate may be overestimated as most other PCNs are managed by conservative treatment.

Surgical intervention generally depends on the location and size of the tumor [13]. Tumors of the head and uncinate process should be treated with pancreatoduodenectomy. Small lesions can also be managed with middle pancreatectomy or tumor enucleation, sparing the pancreatic tissue. Distal pancreatectomy, with or without spleen preservation, should be performed for PCNs identified in the body and tail of the pancreas [29].

In our study, the mortality rate was $0.9 \%$; that is, only one patient died in the perioperative period as a result of pulmonary infection. The overall complication rate was $45.0 \%$. These results are similar to those reported in other literature $[15,30]$. The most common complication was pancreatic fistula; its incidence was highest in the patients who underwent middle pancreatectomy, but there was no significant difference between these surgical treatments. Therefore, middle pancreatectomy is recommended in cases where major pancreatic resection, such as pancreaticoduodenectomy, is not required

PCNs encompass a wide spectrum of benign, borderline, and malignant diseases; the preoperative identification of predictors for malignancy is very critical for subsequent management. Following the primary assessment of the clinical presentation, tumor markers and imaging examinations are recommended for preoperative evaluation. PCNs with elevated serum CEA or CA19-9 should be treated with surgical resection because of the 
high risk of harboring a potentially tumor or malignant lesion [29]. Our statistical analyses confirmed that an elevated CEA and/or CA19-9 is an independent predictive factor for malignant pancreatic cysts $(P=0.011)$. In radiological studies, mural nodules, symptoms associated with the cyst, thick septa, peripheral calcification, and concomitant dilation of the pancreatic duct are features associated with malignancy [1]. CT and MRI scans are both capable of predicting the presence of malignancy in pancreatic cysts more accurately (73 to $79 \%$ ) than other imaging methods in use [31]. In China, EUS is much more commonly used to perform FNA in order to provide fluid for cytological analysis and tumor markers or amylase testing, which plays an important role in diagnosis of PCNs. Although there was a marked increase in the use of EUS/ FNA, EUS alone has been shown to be inadequate for differentiating neoplastic cysts from non-neoplastic cysts because of the considerable overlap between mucinous and non-mucinous cysts [16,32].

From the follow-up data, the prognosis of patients with resected PCNs seems to be favorable. None of our SPN patients died during the study period, which is consistent with the relatively indolent biological properties of this tumor. For mucin-producing tumors, a significantly lower survival rate was found in MCNs $(90.0 \%)$ and IPMNs (87.5\%), consistent with the reports of others $[4,15]$.

\section{Conclusions}

With the widespread use of high-resolution abdominal imaging, the detection rate of PCNs has increased. However, there are still obstacles in the differential diagnosis of various types of PCNs. In recent years, the mortality rate and major complications have decreased with improvements in pancreatic surgery techniques and perioperative management. Favorable long-term survival after resection of PCNs compared to adenocarcinoma has also been obtained. Therefore, aggressive surgical resection is advocated for PCN patients, especially in the case of those with symptoms, elevated CA19-9 or CEA levels, and malignancy features.

\section{Consent}

Written informed consent was obtained from the patient for the publication of this report and any accompanying images.

\footnotetext{
Abbreviations

CA19-9: Carbohydrate antigen 199; CEA: Carcinoembryonic antigen; IPMN: Intraductal papillary mucinous neoplasm; MCN: Mucinous cystic neoplasm; PCN: Pancreatic cystic neoplasms; SCN: Serous cystic neoplasm; SPN: Solid pseudopapillary neoplasm; CT: computed tomography; MRI: magnetic resonance imaging; MRCP: magnetic resonance cholangiopancreatography; EUS/FNA: endoscopic ultrasound/fine needle aspiration; ERCP: endoscopic retrograde cholangiopancreatography.
}

\section{Competing interests}

The authors declare that they have no competing interests.

\section{Authors' contributions}

TBL designed the study and critically revised the manuscript. XLB and LYY collected and analyzed the clinicopathological data. XLB, LYY and QZ drafted the manuscript. PP and JW edited the data. All authors have read and approved the final version of the manuscript.

\section{Acknowledgments}

The authors thank Professor Christopher L Wolfgang, Department of Surgery (The Johns Hopkins University School of Medicine), for editing and revising the article. This work was supported by a grant from the National Natural Science Funds for Distinguished Young Scholar, (grant number 30925033), Innovation and High-Level Talent Training Program of Department of Health of Zhejiang.

Received: 25 December 2013 Accepted: 4 July 2014

Published: 19 July 2014

\section{References}

1. Bai XL, Zhang Q, Masood N, Masood W, Zhang Y, Liang TB: Pancreatic cystic neoplasms: a review of preoperative diagnosis and management. J Zhejiang Univ Sci B 2013, 14:185-194.

2. Fernandez-del Castillo C, Targarona J, Thayer SP, Rattner DW, Brugge WR, Warshaw AL: Incidental pancreatic cysts: clinicopathologic characteristics and comparison with symptomatic patients. Arch Surg 2003, 138:427-423. discussion 433-424.

3. Fitzgerald TL, Hickner ZJ, Schmitz M, Kort EJ: Changing incidence of pancreatic neoplasms: a 16-year review of statewide tumor registry. Pancreas 2008, 37:134-138.

4. Lee KS, Sekhar A, Rofsky NM, Pedrosa I: Prevalence of incidental pancreatic cysts in the adult population on MR imaging. Am J Gastroenterol 2010, 105:2079-2084.

5. Khalid A, Brugge W: ACG practice guidelines for the diagnosis and management of neoplastic pancreatic cysts. Am J Gastroenterol 2007 102:2339-2349.

6. Tanaka M, Fernandez-del Castillo C, Adsay V, Chari S, Falconi M, Jang JY, Kimura W, Levy P, Pitman MB, Schmidt CM, Shimizu M, Wolfgang CL, Yamaguchi K, Yamao K: International consensus guidelines 2012 for the management of IPMN and MCN of the pancreas. Pancreatology 2012, 12:183-197.

7. World Medical Association: Declaration of Helsinki: Ethical principles for medical research involving human subjects. 2013. Available from: http://www.wma.net/en/30publications/10policies/b3/index.html.

8. Bassi C, Dervenis C, Butturini G, Fingerhut A, Yeo C, lzbicki J, Neoptolemos J, Sarr M, Traverso W, Buchler M: Postoperative pancreatic fistula: an international study group (ISGPF) definition. Surgery 2005, 138:8-13.

9. Flejou JF: WHO classification of digestive tumors: the fourth edition. Ann Pathol 2011, 31:S27-S31.

10. Lennon AM, Wolfgang C: Cystic neoplasms of the pancreas. J Gastrointest Surg 2013, 17:645-653.

11. Tseng JF, Warshaw AL, Sahani DV, Lauwers GY, Rattner DW, Fernandez-del Castillo C: Serous cystadenoma of the pancreas: tumor growth rates and recommendations for treatment. Ann Surg 2005, 242:413-419. discussion 419-421.

12. Sarr MG, Murr M, Smyrk TC, Yeo CJ, Fernandez-del-Castillo C, Hawes RH, Freeny PC: Primary cystic neoplasms of the pancreas: neoplastic disorders of emerging importance-current state-of-the-art and unanswered questions. J Gastrointest Surg 2003, 7:417-428.

13. Coelho JC, Valle CL, Ribas BM, Andriguetto LD, Claus CM: Surgical treatment of cystic neoplasms of the pancreas. Arq Gastroenterol 2010 47:135-140.

14. Bassi C, Salvia R, Molinari E, Biasutti C, Falconi M, Pederzoli P: Management of 100 consecutive cases of pancreatic serous cystadenoma: wait for symptoms and see at imaging or vice versa? World J Surg 2003, 27:319-323.

15. Valsangkar NP, Morales-Oyarvide $V$, Thayer SP, Ferrone CR, Wargo JA Warshaw AL, Fernandez-del Castillo C: 851 resected cystic tumors of the pancreas: a 33-year experience at the Massachusetts general hospital. Surgery 2012, 152:S4-S12.

16. Salvia R, Malleo G, Marchegiani G, Pennacchio S, Paiella S, Paini M, Pea A, Butturini G, Pederzoli P, Bassi C: Pancreatic resections for cystic 
neoplasms: from the surgeon's presumption to the pathologist's reality. Surgery 2012, 152:S135-S142.

17. He J, Ahuja N, Makary MA, Cameron JL, Eckhauser FE, Choti MA, Hruban RH, Pawlik TM, Wolfgang CL: 2564 resected periampullary adenocarcinomas at a single institution: trends over three decades. HPB (Oxford) 2014, 16:83-90.

18. Ohashi K, Murakami Y, Maruyama M: Four cases of mucin-producing cancer of the pancreas on specific findings of the papilla of Vater [in Japanese]. Prog Dig Endoscopy 1982, 20:348-351.

19. Baker ML, Seeley ES, Pai R, Suriawinata AA, Mino-Kenudson M, Zamboni G, Kloppel G, Longnecker DS: Invasive mucinous cystic neoplasms of the pancreas. Exp Mol Pathol 2012, 93:345-349.

20. Niedergethmann M, Grutzmann R, Hildenbrand R, Dittert D, Aramin N, Franz M, Dobrowolski F, Post S, Saeger HD: Outcome of invasive and noninvasive intraductal papillary-mucinous neoplasms of the pancreas (IPMN): a 10-year experience. World J Surg 2008, 32:2253-2260.

21. Tollefson MK, Libsch KD, Sarr MG, Chari ST, DiMagno EP, Urrutia R, Smyrk TC Intraductal papillary mucinous neoplasm: did it exist prior to 1980 ? Pancreas 2003, 26:e55-e58.

22. Ye J, Ma M, Cheng D, Yuan F, Deng X, Zhan Q, Shen B, Peng C: Solidpseudopapillary tumor of the pancreas: clinical features, pathological characteristics, and origin. J Surg Oncol 2012, 106:728-735.

23. Ji Y, Lou WH, Jin DY, Kuang TT, Zeng MS, Tan YS, Zeng HY, Sujie A, Zhu XZ: A series of 64 cases of pancreatic cystic neoplasia from an institutional study of China. World J Gastroenterol 2006, 12:7380-7387.

24. Yoon WJ, Lee JK, Lee KH, Ryu JK, Kim YT, Yoon YB: Cystic neoplasms of the exocrine pancreas: an update of a nationwide survey in Korea. Pancreas 2008, 37:254-258.

25. Goh BK, Tan YM, Cheow PC, Chung AY, Chow PK, Wong WK, Ooi LL: Solid pseudopapillary neoplasms of the pancreas: an updated experience. J Surg Oncol 2007, 95:640-644.

26. Tien YW, Ser KH, Hu RH, Lee CY, Jeng YM, Lee PH: Solid pseudopapillary neoplasms of the pancreas: is there a pathologic basis for the observed gender differences in incidence? Surgery 2005, 137:591-596.

27. Patil TB, Shrikhande SV, Kanhere HA, Saoji RR, Ramadwar MR, Shukla PJ: Solid pseudopapillary neoplasm of the pancreas: a single institution experience of 14 cases. HPB (Oxford) 2006, 8:148-150.

28. Morikawa T, Onogawa T, Maeda S, Takadate T, Shirasaki K, Yoshida H, Ishida K, Motoi F, Naitoh T, Rikiyama T, Katayose Y, Egawa S, Unno M: Solid pseudopapillary neoplasms of the pancreas: an 18-year experience at a single Japanese Institution. Surg Today 2013, 43:26-32.

29. Warshaw AL, Rattner DW, Fernandez-del Castillo C, Z'Graggen K: Middle segment pancreatectomy: a novel technique for conserving pancreatic tissue. Arch Surg 1998, 133:327-331.

30. Sheehan MK, Beck K, Pickleman J, Aranha GV: Spectrum of cystic neoplasms of the pancreas and their surgical management. Arch Surg 2003, 138:657-660. discussion 660-652.

31. Lee LS, Clancy T, Kadiyala V, Suleiman S, Conwell DL: Interdisciplinary management of cystic neoplasms of the pancreas. Gastroenterol Res Pract 2012, 2012:513163.

32. Sperti C, Pasquali C, Ferronato A, Pedrazzoli S: Median pancreatectomy for tumors of the neck and body of the pancreas. J Am Coll Surg 2000, 190:711-716.

doi:10.1186/1477-7819-12-228

Cite this article as: Bai et al: Surgical resection and outcome of pancreatic cystic neoplasms in China: analysis of a 16-year experience from a single high-volume academic institution. World Journal of Surgical Oncology 2014 12:228.

\section{Submit your next manuscript to BioMed Central and take full advantage of:}

- Convenient online submission

- Thorough peer review

- No space constraints or color figure charges

- Immediate publication on acceptance

- Inclusion in PubMed, CAS, Scopus and Google Scholar

- Research which is freely available for redistribution 